\title{
Technologies of Reproduction Terry Varieties of Clematis
}

\author{
Khanbabaeva Olga Evgenievna ${ }^{1,2}$, Matsneva Anna Evgenievna ${ }^{1,2}$, Kovaleva Irina Sergeevna ${ }^{3}$, \\ Tazina Svetlana Vitalevna \& Tazin Ivan Ivanovich ${ }^{1,2}$ \\ ${ }^{1}$ Russian State University, RGAU-MSHA named after K. A. Timiryazev, Moscow City, Russia \\ Correspondence: Khanbabaeva Olga Evgenievna, Russian State University, RGAU-MSHA named after K. A. \\ Timiryazev, Moscow City, Russia. E-mail: hanbabaeva@yandex.ru
}

Received: January 3, 2020

doi:10.5539/jas.v12n3p214

\author{
Accepted: February 3, $2020 \quad$ Online Published: February 15, 2020 \\ URL: https://doi.org/10.5539/jas.v12n3p214
}

This research is financed by the "Fruit Growing Laboratory" of the Fruit Experimental Station of the Federal State Budget Educational Establishment of Higher Education, Russian State Autonomous University-Moscow Agricultural Academy Timiryazev.

\begin{abstract}
The paper presents issues of optimizing the technology of growing popular terry varieties of clematis (Clematis L.) in Russia. Trimming groups, bookmark features of flower buds are described. The issues of reproduction and agricultural technology when laying uterine plantations are considered. A comparative analysis of traditional breeding technology with innovative technology (in vitro). The optimal nutrient medium for the stages of micro propagation, cultivation and rooting, enriched with vitamins and other substances. In experiments on green cuttings, 8 terry varieties were used. Estimated rooting of green cuttings by standard propagation technology. Spring cuttings are recommended for the varieties Bellof Woking (83\%), Empress (81\%), Blue Light (79\%) and give a high yield of planting material from one mother plant. Two varieties with low rooting were selected-Purpurea Plena Elegans, Multi Blue. In vitro breeding technology has been developed for them. Accounting and observation of the development of two terry clematis varieties in the tissue culture: Purpurea Plena Elegans, Multi Blue. The aim of our study is to develop a technology for clonally propagation for these varieties, as well as the adaptation of micro plants of these varieties to non-sterile conditions. Therefore, in vitro propagation is recommended for these two varieties. An optimal substrate composition has been developed for the adaptation of clematis plants propagated in vitro, as well as for cuttings. The article provides recommendations for planting, pruning and caring for uterine plantings of clematis with double flowers in sheltered ground.
\end{abstract}

Keywords: clematis, varieties, terry, cuttings, pruning groups, uterine plants, flower buds, rooting, substrate for rooting, in vitro technology

\section{Introduction}

\subsection{The Value of Terry Varieties of Clematis in Horticulture}

Modern garden classifications of clematis are numerous. Some classifications divide varietal clematis into large-flowered (flower diameter $10 \mathrm{~cm}$ or more) and small-flowered (diameter less than $10 \mathrm{~cm}$ ). According to the height of plants (length of vines), clematis is divided into 3 groups: the first - up to $1 \mathrm{~m}$, the second-1.5-2 $\mathrm{m}$ and the third $-2.5-3 \mathrm{~m}$ and higher. Varieties are also classified according to the trim group: from first to third (Ivanova \& Khanbabaeva, 2013).

\subsection{Pruning Varietal Clematis}

To obtain a large number of green cuttings from varietal clematis in protected ground conditions, the use of strong pruning of uterine plants is recommended. Such pruning for 5-7 years of cultivation reduces the productivity of queen cells, but at the same time makes it possible to obtain a sufficient number of green cuttings. Under the condition of intensive use of uterine plants, it is recommended that they be completely replaced after 5-7 years of cultivation. During this time, unwanted viruses and diseases accumulate, so it is advisable to plant new mother liquids clematis with healthy planting material. 
Terry varieties are very popular in gardening and landscaping in Russia. They have abundant and long flowering, large flowers. This group forms a few flowers on the shoots of last year in early summer, provided that the shoots wintered well. And then it gives a very plentiful flowering on the shoots of the current year in the second half of summer.

Since terry is partially associated with the transformation of part of the stamens into petals, the flowering of one flower lasts 5-7 days longer than in varieties with a simple flower.

\subsection{The Appearance of Terry: Importance in Gardening}

Terry flower in garden crops is an important decorative and economic feature. As a rule, in terry flowers, part of the stamens is reduced to petals, and sometimes completely. Most plants with double flowers bloom for a long time, more than 10-14 days. This is due to the lack of pollination. Fully double flowers, do not form seeds and have no aroma.

Terry flower is closely associated with polyploidy and mutagenesis. Polyploidy-hereditary changes associated with an increase in the number of whole chromosome sets. Polyploid plants are characterized by prolonged flowering, a larger flower, a corrugated edge of the petals, and high resistance to adverse environmental factors. Studies on polyploidy were carried out on a culture of iris bearded (Germanic) (Stern, 1956).

However, directly the double flower is associated with mutations that occurred during meiotic cell division. Mutations are sudden hereditary changes that represent the genetic basis of variability. Terry is a morphological somatic mutation. In ornamental plants, somatic mutations were found in color, shape and degree of terry of the flower.

Since they occur spontaneously and rarely in nature, in order to obtain terry, they use treatment or irradiation of plants with special substances-mutagens that cause the desired mutation (Khanbabaeva, 2011).

The combination of mutagenesis with hybridization is the most promising way in the selection of flower cultures. This combination accelerates the process of creating new varieties (Dryagina \& Kudryavets, 1986).

\subsection{Technology of Microclonal Propagation of Ornamental Plants}

The culture of isolated tissues is used for propagation and for healing from viruses and other pathogens of planting material. This method is called clonally micro propagation of plants, allowing you to get hundreds of thousands of plants per year from one meristem. And also this method is used in plant breeding to produce fast-growing, resistant to pests and adverse environmental factors of plants (Kalashnikova \& Rodin, 2004).

For clematis, this method is used only if, using standard propagation technology, a low reproduction rate is obtained.

Thus, the aim of our study is to select the optimal technology for the propagation of terry clematis varieties, characterized by low rooting and the yield of standard planting material with the traditional method of propagation. And also, the selection of substrate for the adaptation of micro plants of clematis varieties propagated in vitro.

\section{Method}

\subsection{Objects of Study}

The most common varieties belonging to the group of large-flowered terry varieties: Bellof Woking, Blue Light, Crystal Fountain, Empress, Evijohil, Mazury, Multi Blue, Purpurea Plena Elegans.

\subsection{Technology of Green Cuttings}

Terry varieties are propagated mainly by the vegetative method, using traditional technology-green cuttings or innovative-microclonal propagation.

Uterine plants of 7 varieties are located in protected ground, in a glazed, heated greenhouse. The age of the uterine plants is approximately 5-6 years. Grown under standard agricultural technology, in ridges, with a garter to the support.

Cuttings were carried out in two terms - spring and summer. In rooted cuttings, the length $(\mathrm{cm})$ and the number of roots (pcs) were taken into account, and the percentage of rooting of each variety (\%) was calculated.

For rooting, a substrate containing lowland peat, perlite $(3: 1)$ and mineral additives was used. 


\subsection{Technology of Reproduction in vitro}

As the primary explants, shoot apexes taken from uterine plants in early March were used. The mother liquors are planted in ridges in the conditions of a heated winter greenhouse.

Before sterilization, the selected plant material was washed in running water with the addition of surfactants (surfactants) to remove contaminants for 9 minutes. Then the explants were treated with $70 \%$ ethanol for $2-3$ seconds, then with $2.5 \%$ sodium hypochlorite solution for 7 minutes. Then the plant material was washed several times with sterile distilled water. Sterile explants were placed in test tubes on the Murasig-Skoog agar medium (MS) enriched with the following substances ( $\mathrm{mg} / \mathrm{L}$ ): thiamine (B1), pyridoxine (B6), nicotinic acid (PP)-0.5; inositol-100, 6-BAP-1; sucrose-30,000, bacto-agar-7,000.

At the stage of micro propagation, the culture was planted in $250 \mathrm{ml}$ glass vessels of $10 \mathrm{pcs}$. in each. The cultures were incubated in a light room at a light intensity of 1500-2000 lux, a temperature of $220{ }^{\circ} \mathrm{C}$ and a 16-hour photoperiod.

After the cultivation period, the height of the shoots, the number of additional shoots, and the number of nodes were taken into account. The multiplication factor was the sum of the single-node segments.

For the initiation stage, we used a nutrient medium based on mineral salts Murashige-Skoog (MS), enriched with the following substances $(\mathrm{mg} / \mathrm{L})$ : vitamins B1, B6, PP of 0.5; iron 10000; inositol 100; glycine 1000; bacto-agar 7000; sucrose 30000 with the addition of VAR 0.1 .

The percentage of contamination was $20 \%$. At the stage of crop initiation, the duration of which was 5 weeks, conglomerates consisting of 1-2 shoots were formed on the explants. For further replication, conglomerates were divided into single microprobe and planted on fresh nutrient medium in $250 \mathrm{ml}$ plastic containers.

At the stage of micro propagation proper, we used a nutrient medium based on the Murashige-Skoog mineral salts, enriched with the following substances $(\mathrm{mg} / \mathrm{L})$ : vitamins B1, B6, PP of 0.5; iron 10000; inositol 100; glycine 1000, bacto-agar 7000; sucrose 30000 with the addition of the following concentrations of hormones (numbers-option numbers): 1 . VAR $0.1 \mathrm{mg} / \mathrm{L} ; 2$. VAR $0.2 \mathrm{mg} / \mathrm{L} ; 3$. VAR $0.3 \mathrm{mg} / \mathrm{L} ; 4$. VAR $0.4 \mathrm{mg} / \mathrm{L} ; 5$. VAR 0.1 mg/L, 2-ip $1.0 \mathrm{mg} / \mathrm{L} ; 6$. VAR $0.1 \mathrm{mg} / \mathrm{L}, 2$-ip $3.0 \mathrm{mg} / \mathrm{L} ; 7$. VAR $0.1 \mathrm{mg} / \mathrm{L}, 2$-ip $5.0 \mathrm{mg} / \mathrm{L} ; 8.2$-ip $1.0 \mathrm{mg} / \mathrm{L} ; 9.2$-ip $3.0 \mathrm{mg} / \mathrm{L} ; 10.2-i p 5.0 \mathrm{mg} / \mathrm{L}$.

After the cultivation period, the height of the shoots, the number of additional shoots in one conglomerate, the number of nodes, percent rooting, and the length of the roots were taken into account. The multiplication factor was the sum of the single-node segments. The volume of each option was 20 explants.

Statistical data processing was performed using analysis of variance and the SPSS Statistics package.

\section{Results and Discussion}

The best propagation method for most terry clematis varieties is green cuttings (Figure 1).

Terry varieties can also be propagated by layering and dividing the bush. Laying out overwintered shoots in the spring around the bush, hilling them, you can get several rooted plants in 30-45 days. The division is best done in the spring, before the buds open. But the reproduction rate with such methods is not high.

When propagating such varieties of clematis by green cuttings, the following features should be taken into account. If reproduction occurs in a winter greenhouse, then the first cuttings should be carried out in late March-early April. To do this, in the fall it is necessary to apply a strong pruning of the uterine bushes, that is, remove all shoots to a height of $20-30 \mathrm{~cm}$, which will allow you to adjust the tailoring intensity and the growth rate of the growing shoots. There will be no flowering on last year's shoots, as they are not preserved. But in the spring, shoots on the uterine bushes begin to grow rapidly, reaching a gain of up to $10 \mathrm{~cm}$ per day. Cuttings begin from the stage of budding. In spring cuttings, shoots, as a rule, have a large number of nodes (more than 8-10 pieces) and flower buds are laid closer to the top of the shoot, which significantly increases the yield of cuttings.

For rooting, cuttings are used only with vegetative buds in the axils of the leaves. Such cuttings are well rooted and quickly give growth. When rooting cuttings with generative buds in the axils of the leaves, the rooting percentage drops sharply, and there is no growth of shoots.

Terry varieties may be cut during the summer, but a number of difficulties arise in the summer. With an increase in air temperature (more than $25^{\circ} \mathrm{C}$ ), the number of nodes with each subsequent pruning is reduced in uterine plants. Flower buds are laid lower and lower, by the end of the season it is already 3-4 knots from the ground. At the same time, the yield of cuttings from the uterine plant is significantly reduced. Therefore, in June-July it is better not to cuttings, but to allow the plants to bloom and prune in early August, so that by the end of August, 
when the temperature drops to $18-20^{\circ} \mathrm{C}$, shoots with sufficiently high flower buds can be obtained. However, it is necessary to ensure that the temperature during rooting of cuttings in autumn does not drop below $15{ }^{\circ} \mathrm{C}$. If rooted cuttings remain in the greenhouses for the winter, then you need to provide them with a sufficient amount of light.

The study examined the rooting of the eight most common terry clematis varieties: Bellof Woking, Blue Light, Crystal Fountain, Empress, Evijohil (Josephine), Fair Rosamond, Multi Blue, Purpurea Plena Elegans.

Table 1. Rooting of green cuttings of the studied varieties of clematis, 2018-2019

\begin{tabular}{llll}
\hline No. & Sort & The rooting of spring cuttings $(\%)$ & The rooting of summer cuttings $(\%)$ \\
\hline 1. & Bellof Woking & 83 & 49 \\
2. & Blue Light & 79 & 56 \\
3. & Crystal Fountain & 65 & 50 \\
4. & Empress & 81 & 45 \\
5. & Evijohil & 62 & 40 \\
6. & Multi Blue & 39 & 16 \\
7. & Fair Rosamond & 73 & 50 \\
8. & Purpurea Plena Elegans & 35 & 10 \\
\hline
\end{tabular}

According to the data obtained, it can be concluded that most varieties give a large yield of cuttings during spring cuttings. Especially worthy of note are the varieties: Bellof Woking (83\%), Empress (81\%), Blue Light $(79 \%)$. They gave the highest rates of rooting in the spring period of cuttings. Therefore, for the industrial propagation of these varieties, the traditional method is recommended-green cuttings (Table 1).

Two varieties (Purpurea Plena Elegans, Multi Blue) showed a low rooting percentage at two grafting periods; therefore, in vitro propagation technology is used for them (Korotkov \& Korotkova, 2005).

Most varieties from the terry clematis group are imported from warm European regions, so plants need time to adapt to growing conditions to plant uterine plantings and landscaping. It is necessary to optimize the soil conditions, illumination, irrigation and top dressing, so that the plants take root better, take root and winter successfully.

Planting of young plants can be carried out almost throughout the growing season, but it is preferable to do everything in the early spring or autumn. For the arrangement of mother plants, it is better to use two-year-old seedlings in containers (with a closed root system), with well-developed 6-10 roots about 10-15 cm long.

For planting, choose a well-lit place, and the lower part of the plant may be in partial shade, which will favorably affect the growth of the vine. Shoots need strong support and protection from strong winds. Clematis does not tolerate stagnation of water in the root zone; this is one of the main causes of their death (McMillan Brown, 1987).

The plant is planted in a spacious $(60 \times 60 \times 60 \mathrm{~cm})$ pit with loose, nutritious soil, deepening the root neck by 1-2 knots (about $8 \mathrm{~cm}$ ). From the buried buds, a tailoring center forms over time, and subsequently strong, abundantly flowering bushes develop that do not suffer from frost and overheating. However, weak seedlings cannot be deeply buried, as this will impede the development of young shoots. For planting, a light nutrient substrate is prepared in advance from peat, turf land, sand, and compost. Moreover, the acidity of the substrate should be in the range of pH 7.5-8 (slightly alkaline). Since most fertilizers acidify loamy and clay soil, when planting on these types of soils, you can add organic fertilizers or deoxidize the soil with lime.

Clematis, like all beautifully flowering vines, is responsive to the application of mineral fertilizers, especially trace elements. It is advisable to make basic fertilizers under the root in the first half of summer, combining this with foliar dressing with microelements (spraying on leaves). Extra root top dressings containing molybdenum, cobalt, silicon are especially effective. During the season, 3-4 such top dressings are carried out. Plants bloom profusely, leaves turn dark green (Sokolova, 2010).

For wintering, the vine should be removed from the supports and laid on the ground. In the early years of laying queen cells it is advisable to use a light shelter. You can cover it with peat, sawdust, light non-woven material.

Liana reaches decorativeness on the 3-5th year after planting, depending on the variety and growing conditions. In one place it can grow up to 30 years. 
Thus, all the studied terry varieties are recommended for use in landscaping and landscape design (Ivanova \& Khanbabaeva, 2013).

Subject to the above rules of agricultural technology, these varieties can be successfully propagated in nurseries of ornamental crops in winter glazed greenhouses, grow protected ground and obtain high-quality planting material (Khanbabaeva, 2013).

Table 2. Features of the development of clematis cultivars Purpurea Plena Elegans and Multi Blue in an in vitro culture, depending on the composition of the nutrient medium after 10 weeks of cultivation

\begin{tabular}{|c|c|c|c|c|c|c|c|c|}
\hline \multirow{2}{*}{$\begin{array}{l}\text { Hormone concentration } \\
(\mathrm{mg} / \mathrm{L})(\text { Option number })\end{array}$} & \multicolumn{2}{|c|}{$\begin{array}{l}\text { Shoot length } \\
(\mathrm{cm})\end{array}$} & \multicolumn{2}{|c|}{$\begin{array}{l}\text { Reproduction } \\
\text { coefficient }\end{array}$} & \multicolumn{2}{|c|}{$\begin{array}{l}\text { Root length } \\
(\mathrm{cm})\end{array}$} & \multicolumn{2}{|c|}{$\begin{array}{c}\text { Spontaneous } \\
\text { rhizogenesis }(\%)\end{array}$} \\
\hline & PPE & MB & PPE & $\mathrm{MB}$ & PPE & $\mathrm{MB}$ & PPE & MB \\
\hline 1) BAP 0.1 & 4.2 & 2.2 & 4.7 & 4.5 & 2.7 & 0 & 70 & 0 \\
\hline 2) $\mathrm{BAP} 0.2$ & 3.5 & 1.9 & 6.1 & 4.0 & $\underline{3.8}$ & 0 & 60 & 0 \\
\hline 3) $\mathrm{BAP} 0.3$ & 3.8 & 1.2 & $\underline{7.7}$ & $\underline{4.2}$ & 7.7 & 0 & 30 & 0 \\
\hline 4) $\mathrm{BAP} 0.4$ & 4.6 & 1.9 & 6.4 & 4.6 & 6.4 & 2.1 & 20 & 10 \\
\hline 5) BAP $0.1,2$-IP 1.0 & 3.5 & $\underline{1.6}$ & 5.3 & 4.4 & $\underline{4.0}$ & 4.1 & 10 & 20 \\
\hline 6) BAP $0.1,2$-IP 3.0 & $\underline{3.2}$ & $\underline{1.7}$ & 5.2 & 3.0 & 0 & 0 & 0 & 0 \\
\hline 7) BAP 0.1, 2-IP 5.0 & 2.3 & 2.1 & 3.8 & 3.6 & 0 & 0 & 0 & 0 \\
\hline 8) 2-IP 1.0 & 4.9 & 2.1 & 6.1 & 2.8 & 0 & 0 & 0 & 0 \\
\hline 9) 2-IP 3.0 & $\underline{3.3}$ & 1.3 & 5.4 & 3.1 & 1,1 & 0 & 0 & 0 \\
\hline 10) 2-IP 5.0 & 2.0 & 1.9 & 2.5 & 3.3 & 0 & 0 & 0 & 0 \\
\hline НCР05 & 0.1 & 0.1 & - & - & 0.8 & 1.1 & - & - \\
\hline
\end{tabular}

Note. PPE: grade Purpurea Plena Elegans; MB: grade Multi Blue; 3.3: differences between options are not significant.

If the difference between the options is more than the value of HCP05, then the differences on this basis are significant (Smiryaev \& Kilchevsky, 2007). If the difference between the values is less than the value of HCP05, then the differences are not significant and, accordingly, the options do not differ. For example, according to the characteristic "shoot length, $\mathrm{cm}$ " in the Purpurea Plena Elegans cultivar, differences between options 6 and 9 are not significant and the options do not differ. Similarly, for options No. 2 and No. 5 on the basis of "Length of roots, cm" (Table 2).

For spontaneous rhizogenesis, it should be noted Option $1(70 \%)$ and $2(60 \%)$ for the Purpurea Plena Elegans variety. This variety has a high percentage of spontaneous rhizogenesis of $70 \%$ in a medium supplemented with a hormone in a BAP concentration of $0.1 \mathrm{mg} / \mathrm{L}$. This feature of the variety for spontaneous rhizogenesis can be used and apply for it a one-stage technology of reproduction and rooting in one nutrient medium.

The Purpurea Plena Elegans variety had the highest breeding coefficient of 7.7 in Option 3 on a medium supplemented with a hormone of BAP concentration of $0.3 \mathrm{mg} / \mathrm{L}$, while the height of the microprobe is $3.8 \mathrm{~cm}$, the number of microprobe for 1 explants is 2-3. This medium can be recommended for use at the stage of micro propagation itself (Figure 1).

In the Multi Blue variety, the highest multiplication factor of 4.6 was observed in Option 4 on a medium supplemented with a hormone at a BAP concentration of $0.4 \mathrm{mg} / \mathrm{L}$. At the same time, the height of microprobe is $1.9 \mathrm{~cm}$, conglomerates with the number of microprobe 2-4 pieces are formed. In the Multi Blue variety, spontaneous rhizogenesis was $10-20 \%$ (Figure 2).

Options 2 and 4 should also be recommended for use, giving a high reproduction rate for both varieties.

According to the results of the experiments, it was decided to use a medium with the addition of a hormone in a concentration of BAP of $0.3 \mathrm{mg} / \mathrm{L}$ and BAP of $0.4 \mathrm{mg} / \mathrm{L}$ for the propagation of micro plants depending on the variety.

At the rooting stage, an optimal nutrient medium based on half concentrations of the Murashige-Skoog (MS) mineral salts is enriched with the following substances $(\mathrm{mg} / \mathrm{L})$ : vitamins B1, B6, PP $0.5 \mathrm{mg} / \mathrm{L}$; iron 10000; inositol 100; glycine 1000; bacto-agar 7000; sucrose 20,000 with the addition of the hormone IMC $0.2 \mathrm{mg} / \mathrm{L}$. Cuttings with two nodes were planted for rooting. 
The rooting stage lasts about $8-10$ weeks. The rooting rate is $70 \%$ for the Multi Blue variety (Figure 2), and $80 \%$ for the Purpurea Plena Elegans variety (Figure 1).

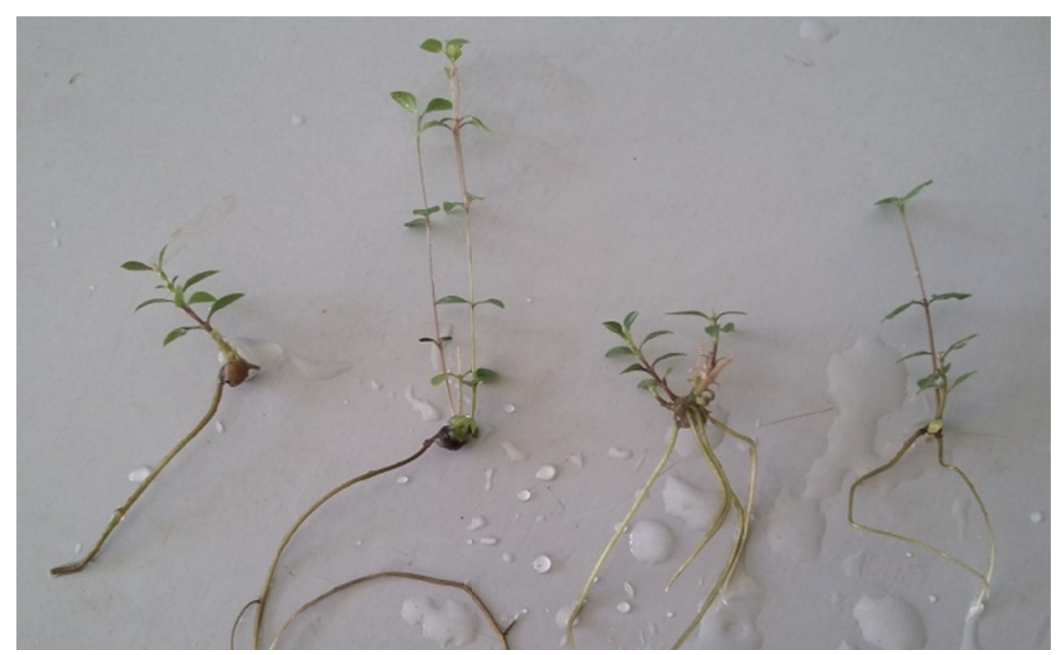

Figure 1. Micro plants of Clematis cultivar Purpurea Plena Elegans

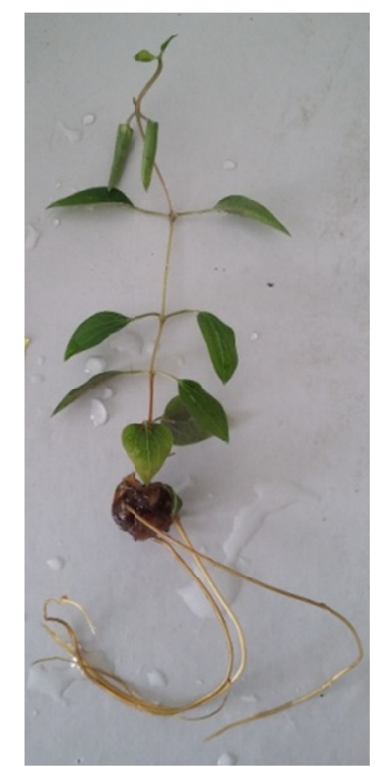

Figure 2. Micro plants varieties of Clematis Multi Blue

One of the important stages is the stage of adaptation of micro plants. In the process of reproduction, test-tube plants undergo anatomical and morphological and physiological changes: micro boots grown in tissue culture have low photosynthetic activity, poor water balance, roots, do not have root hairs, and function poorly (Butenko, 1975).

Adaptation to non-sterile conditions was carried out in a Veltorf brand substrate with the following recipe: horse peat, fraction 5-20 mm, PG mix fertilizer $1.2 \mathrm{~kg} / \mathrm{m}^{3}$, wetting agent $0.1 \mathrm{~L} / \mathrm{m}^{3}$, agroperlite $10 \%$. The yield of plants during the adaptation of micro plants of two varieties was $90-95 \%$. Three weeks later, young plants were released from the water-retaining film. Transplantation from cartridges into plastic containers was performed after six weeks (42 days). Plants transplanted from the cassettes fell into a relatively short dormant period, after transplanting, for about two weeks (14 days).

In vitro clematis plants of the first year differed from clematis plants obtained by green cuttings using thinner shoots (Figure 3). But after overwintering in a greenhouse, clematis plants obtained by the in viro method noted 
an active growth of more powerful shoots (1-2 pieces) and seedlings were in no way inferior to plants obtained by the green cuttings method (Figure 4).

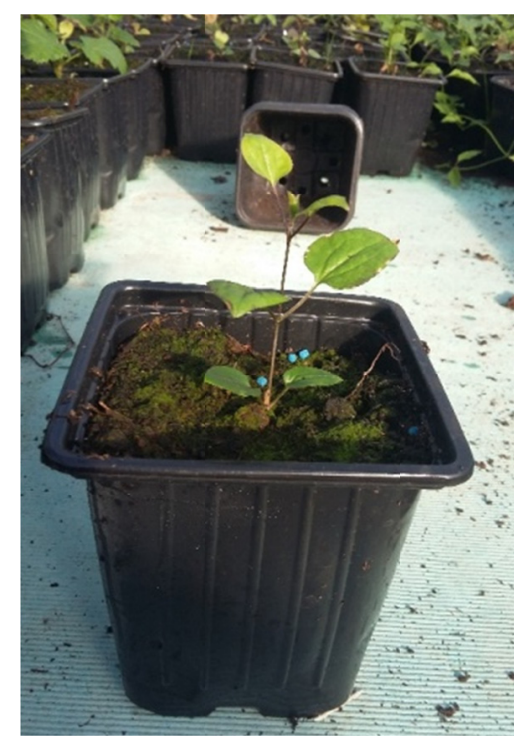

Figure 3. Clematis seedling of Purpurea Plena Elegans cultivar 1 month after transplantation from cassettes, the first year of cultivation

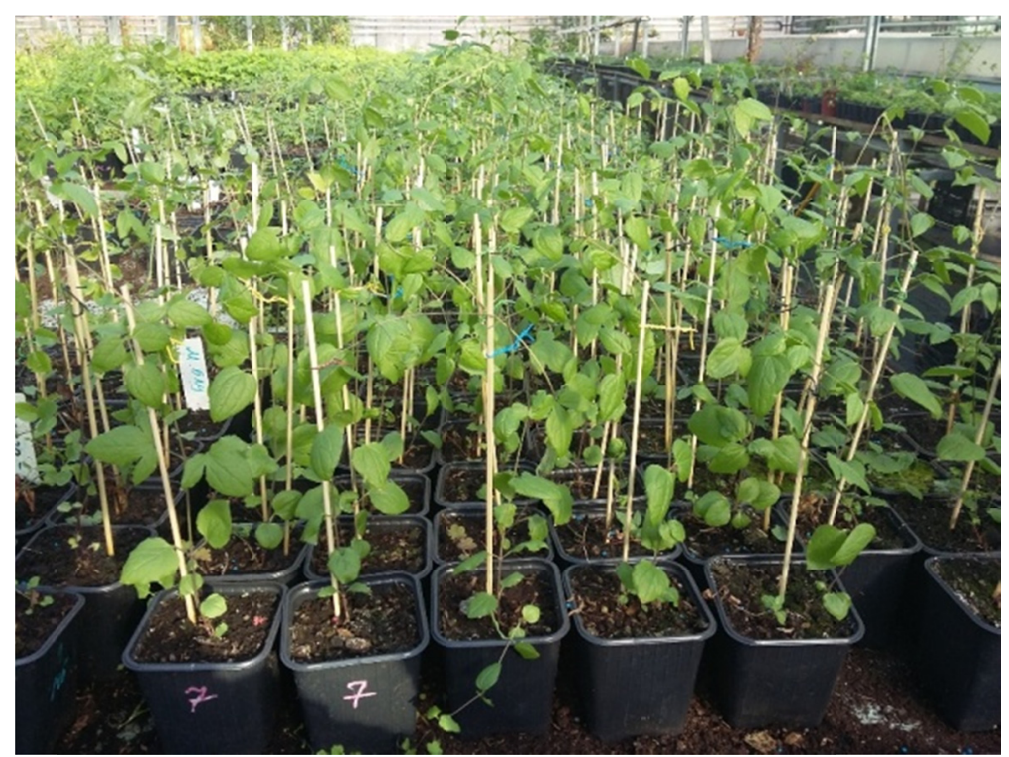

Figure 4. Clematis seedling Purpurea Plena Elegans cultivar, second year of cultivation

\section{Conclusions}

Thus, for most of the studied terry varieties of clematis, propagation is by way of cuttings. For a larger yield of planting material, spring cuttings in March are recommended. This requires the presence of uterine plants in a protected ground. Uterine plants should be kept at a high level of agricultural technology. To obtain more cuttings, a short pruning of uterine plants is recommended, as in varieties of the third group. It is recommended that the following varieties be propagated by the green cuttings method according to standard technology: Bellof Woking, Empress, Blue Light. They gave the highest rates of rooting in the spring period of cuttings. For two varieties Purpurea Plena Elegans and Multi Blue, which are characterized by low rooting using traditional technology, in vitro propagation is recommended. The maximum reproduction rate for these varieties was 
obtained on MS nutrient medium with the addition of BAP hormones $0.2-0.4 \mathrm{mg} / \mathrm{L}$ (Options 2, 3, 4). To adapt micro plants to non-sterile conditions, horse mineralized peat with agroperlite is used. The growing time of planting material using the technology of cuttings is 4 months, with the technology of clonally propagation - 5-6 months.

\section{References}

Anonymous. (2001). An Illustrated Encyclopedia of Clematis (p. 425). Timber Press.

Butenko, R. G. (1975). Experimental morphogenesis and differentiation in plant cell culture: 35th Timiryaz (p. 59). Nauka.

Dryagina, I. V., \& Kudryavets, D. B. (1986). Selection and seed production of flower crops (p. 256). Agropromizdat.

Ivanova, I. V., \& Khanbabaeva, O. E. (2013). Ornamental gardening with the basics of landscape design (Volume Part 2, p. 179). RGAU-ICCA, Moscow.

Kalashnikova, E. A., \& Rodin, A. R. (2004). Obtaining planting material of woody, floral, and herbaceous plants using biotechnological methods: A training manual (3rd ed., p. 84). MGUL.

Khanbabaeva, O. E. (2011). Gametophytic self-incompatibility in the selection of snapdragon (Antirrhinum majus L.) (p. 143). Publishing House of the Russian State Autonomy and Agricultural Academy named after K.A. Timiryazeva.

Khanbabaeva, O. E. (2013). Multimedia study guide "Reproduction of ornamental plants", certificate number RU 201320650, KAA RGAU-MSHA Timiryazev, Moscow. DBMS version: Power Point (Volume 48.8).

Korotkov, O. I., Korotkova, O. O., \& Mironova, O. Yu. (2005). Clematis in vitro: Materials of the Intern (pp. 221-224). Scientific Conf. "Physiological and molecular genetic aspects of biodiversity conservation and rational use of plant resources", Moscow.

McMillan Brown, F. (1987). Plant propagation (p. 192).

Smiryaev, A. V., \& Kilchevsky, A. V. (2007). Genetics of populations and quantitative traits (p. 272). Kolos.

Sokolova, T. A. (2010). Sokolova \& I. Yu. Bochkova (Eds.), Ornamental crop production: Floriculture: A textbook for students (4th ed., p. 432). T. A. Publishing Center “Academy".

Stern, F. (1956). The evolution of garden irises. Polyploidy (pp. 263-270).

\section{Copyrights}

Copyright for this article is retained by the author(s), with first publication rights granted to the journal.

This is an open-access article distributed under the terms and conditions of the Creative Commons Attribution license (http://creativecommons.org/licenses/by/4.0/). 